\title{
Autosomal Recessive Polycystic Kidney Disease
}

National Cancer Institute

\section{Source}

National Cancer Institute. Autosomal Recessive Polycystic Kidney Disease. NCI

Thesaurus. Code C84579.

Polycystic kidney disease inherited in an autosomal recessive pattern. Patients present with progressive renal failure early in life. The autosomal recessive trait is associated with abnormalities of chromosome 6. 